\title{
Substituição Total do Farelo de Soja por Uréia ou Amiréia, em Dietas com Alto Teor de Concentrado, sobre a Amônia Ruminal, os Parâmetros Sangǘneos e o Metabolismo do Nitrogênio em Bovinos de Corte ${ }^{1}$
}

\section{Reinaldo Cunha de Oliveira Junior ${ }^{2}$, Alexandre Vaz Pires ${ }^{3}$, Juliano José de Resende Fernandes ${ }^{2}$, Ivanete Susin 3 , Flávio Augusto Portela Santos ${ }^{3}$, Rafael Canonenco de Araújo ${ }^{4}$}

\begin{abstract}
RESUMO - Seis novilhos da raça Nelore, não castrados, com peso médio inicial de 420 kg, distribuídos em delineamento em quadrado latino 3x3 duplicado, foram utilizados para avaliar a substituição total de uma fonte de proteína verdadeira (farelo de soja), em uma dieta deficiente em proteína degradável no rúmen (PDR), por uréia ou amiréia (fontes de nitrogênio não protéico), ambas em uma dieta adequada em PDR. As dietas foram isoprotéicas (13,0\%) utilizando-se o bagaço de cana-de-açúcar in natura (BIN) como única fonte de volumoso (20\% da MS). Foram avaliados: a concentração de amônia ruminal, nitrogênio uréico plasmático, glicose plasmática e o metabolismo do nitrogênio. Os tratamentos foram: 1) farelo de soja (FS); 2) uréia e 3) amiréia (A-150S). A concentração de nitrogênio amoniacal no fluido ruminal foi superior no tratamento com uréia, comparado ao tratamento com farelo de soja, sendo que o tratamento com amiréia não diferiu dos demais. O tratamento com amiréia apresentou maior perda de $\mathrm{N}$ urinário. A retenção de $\mathrm{N}$ (g/d e \% do consumido) e o valor biológico da proteína (N retido, \% do N digerido) foram superiores para o tratamento com uréia, comparado aos demais. A concentração de nitrogênio uréico no plasma e a concentração de glicose plasmática foram similares entre os tratamentos. A substituição total do farelo de soja por uréia, ajustando a PDR na dieta de bovinos de corte, demonstrou ser viável. A uréia na forma convencional apresentou vantagens em relação à amiréia.
\end{abstract}

Palavras-chave: amiréia, amônia ruminal, balanço de nitrogênio, parâmetros sangüíneos

\section{Total Replacement of Soybean Meal by Urea or Starea in High Grain Diets on Nitrogen Metabolism, Ruminal Ammonia-N Concentration and Blood Parameters in Beef Cattle}

\begin{abstract}
Six Nellore bulls, with initial body weight of $420 \mathrm{~kg}$, were assigned to a duplicated 3x3 Latin square design to evaluate the effects of replacing a true protein source (soybean meal), of high biological value, in a rumen degradable protein (RDP) deficient diet, by urea or starea (a supposedly slow release nonprotein nitrogen source), both in a RDP adjusted diet. In natura sugarcane bagasse as the only source of forage (20\% of DM). Evaluated parameters were: rumen ammonia-N concentration, plasma urea-N, glucose and nitrogen balance. Experimental treatments were: 1) soybean meal (SBM); 2) urea and 3) starea (A-150S). Diets were isonitrogen (13\% CP). The rumen ammonia-N concentration was higher in the treatment with urea, compared to the treatment with SBM, and starea showed no difference compared to the others. Starea had higher loss of urinary N. N retention ( $\mathrm{g} / \mathrm{d}$ and \% of consumed) and protein biological value ( $\mathrm{N}$ retention, \% of $\mathrm{N}$ digestible) were higher for urea treatment, compared to the others. There was no difference on plasma urea-N and glucose concentration among treatments. Total replacement of SBM by urea, adjusting PDR in diets for growing beef cattle, demonstrated to be viable. Conventional urea showed advantage compared to starea.
\end{abstract}

Key Words: starea, blood parameters, nitrogen balance, ruminal ammonia-N, beef cattle

\section{Introdução}

O modelo de proteína metabolizável proposto no NRC(1996) divide as estimativas das exigências protéicas em proteína degradável no rúmen (PDR), que deve suprir as exigências dos microrganismos ruminais eproteína não degradável no rúmen (PNDR), que deve complementar a proteína microbiana que chega no abomaso. Isto foi um avanço, pois sabe-se que é de fundamental importância a síntese de proteína microbiana e, para que esta ocorra, é necessário que se tenha PDR, em quantidade e qualidade ( $\mathrm{NH}_{3}$, peptídeo e aminoácidos; Russell et al., 1992), a fim de se atingir a máxima eficiência. As exigências de proteína citadas pelo NRC (1996) geralmente são superiores às do NRC (1984), devido, principalmente, ao componente microbiano (PDR).

\footnotetext{
${ }^{1}$ Parte da tese de doutorado do primeiro autor - ESALQ/USP.

2 Doutorandos do Depto. de Zootecnia - ESALQ/USP, C.P. 09 - CEP: 13418-900, Piracicaba, SP (reinaldocoj@yahoo.com.br).

3 Professores do Depto. de Zootecnia - ESALQ/USP, C.P. 09 - CEP: 13418-900, Piracicaba, SP (alvpires@esalq.usp.br).

${ }^{4}$ Mestrando do Depto. de Zootecnia - ESALQ/USP.
} 
Utilizando novilhos em terminação, Stiles et al. (1975) observaram menor concentração de amônia ruminal no tratamento com amiréia quando comparada à uma mistura de uréia mais sorgo moído grosso (quebrado), após sete dias de alimentação. A amiréia proporcionou valores que não diferiram da mistura uréia mais sorgo moído fino ou sorgo extrusado. Com isso, torna-se necessário avaliar a amiréia quanto à liberação gradativa de amônia no rúmen, redução na amônia ruminal e "proteção de cocho", diminuindo os possíveis riscos de intoxicação dos animais.

Os microrganismos ruminais são capazes de sintetizar proteína microbiana a partir de amônia e esqueleto carbônico, podendo as fontes de nitrogênio não protéico (amiréia e uréia) serem fornecedoras de amônia. Uma fonte de nitrogênio não protéico com liberação lenta de amônia teria vantagens de aumentar a disponibilidade da mesma para síntese microbiana e reduzir problemas com toxidez (Bartley \& Deyoe, 1975).

O organismo gasta energia considerável para converter amônia em uréia a fim de evitar a toxicidade por $\mathrm{NH}_{3}$ (Swenson \& Reece, 1996). As concentrações de uréia sangüínea têm sido utilizadas para monitorar o consumo de proteína dietética (teor e degradabilidade ruminal) próximo às exigências do animal, já que o consumo excessivo de proteína pode afetar o desempenho reprodutivo do animal, aumentando sua exigência em energia, ou ainda, o custo da ração (Broderick \& Clayton, 1997). Assim, é importante avaliar a uréia sangüínea quando se utilizam fontes nitrogenadas com diferentes degradabilidades ruminais.

Comparações entre uréia e amiréia na retenção de nitrogênio em borregos (Shiehzadeh \& Harbers, 1974; Silva et al., 1994; Salman et al., 1997) ou em vacas lactantes (Teller et al., 1982; Teller \& Godeau 1986) têm apresentado resultados diversos, não permitindo uma conclusão sobre o assunto. Há uma deficiência em trabalhos que avaliem o balanço de nitrogênio em bovinos de corte, pois a amiréia apresenta fonte de amido com alta taxa de degradação e suposta liberação mais lenta de amônia. Com isso, é de se esperar maior síntese de proteína microbiana, que apresenta alto valor biológico e, portanto, maior retenção de nitrogênio.

Objetivou-se com o presente trabalho comparar os efeitos da substituição total do farelo de soja, em uma dieta deficiente em PDR, por uréia ou amiréia (fontes de nitrogênio não protéico), estando as duas últimas em uma dieta adequada em PDR, utilizando o bagaço de cana-de-açúcar in natura (BIN) como única fonte de volumoso (20\% da MS), sobre a concentração de amônia ruminal, o metabolismo do nitrogênio e a glicose plasmática em bovinos de corte confinados.

\section{Material e Métodos}

Foram utilizados seis novilhos mestiços da raça Nelore com cânula no rúmen, com peso médio inicial de $420 \mathrm{~kg}$, distribuídos em quadrado latino 3x3 duplo. Os animais foram alojados em baias individuais cobertas, do tipo "tie stall" ( 1 x 2,2 m), providas de bebedouros automáticos e cocho para alimentação.

Os animais foram alimentados com dietas contendo bagaço de cana-de-açúcar in natura (BIN) como volumoso (20\%) e $80 \%$ de concentrado com base na matéria seca (Tabela 1), sendo os tratamentos experimentais feitos pela substituição total da fonte de proteína verdadeira (farelo de soja), em uma dieta deficiente em PDR, por uréia ou amiréia (fonte de nitrogênio não protéico de suposta liberação gradativa de nitrogênio), sendo as fontes de nitrogênio não protéico utilizadas em dieta adequada em PDR. Os tratamentos foram formulados para resultarem em dietas isoprotéicas e isoenergéticas, utilizando o programa do NRC (1996) de bovinos de corte.

As fontes de NNP utilizadas foram: uréia agrícola e uréia extrusada, utilizando-se o milho como fonte de amido (Amiréia $150 \mathrm{~S}^{\circledR}$, Pajoara indústria e comércio, Campo Grande, MS).

Na hora do fornecimento da alimentação, o BIN e o concentrado, nas suas respectivas proporções (20:80\%) com base na MS, foram misturados manualmente e fornecidos como ração completa duas vezes ao dia, às 6 e $18 \mathrm{~h}$.

O período experimental teve duração de 84 dias, sendo os primeiros 30 dias destinados ao processo de adaptação dos animais às instalações e às dietas experimentais e o restante do período, segmentado em três subperíodos de 18 dias, sendo destinado aos 14 primeiros dias dos subperíodos para adaptação dos animais às novas dietas e os quatro últimos dias, para colheita de dados e amostras.

$\mathrm{O}$ alimento oferecido e as sobras foram pesados diariamente para determinação do consumo de matéria seca (MS) por animal/dia, durante os quatro últimos dias de cada subperíodo. As amostras foram compostas por animal e subperíodo e conservadas congela-

\footnotetext{
R. Bras. Zootec., v.33, n.3, p.738-748, 2004
} 
das a $-10^{\circ} \mathrm{C}$ para posterior análises.

A colheita total de fezes foi realizada durante 48 horas (15ํ e 16ำ dias) de cada subperíodo, sendo estas pesadas, com intervalos de 12 horas, para determinação da quantidade de fezes excretadas em kg de matéria seca. Foi feita amostragem de 5\% das fezes totais, sendo compostas por animal e por subperíodo. As amostras foram conservadas a $-10^{\circ} \mathrm{C}$ até o término do experimento.

As amostras do alimento oferecido, das sobras e fezes foram secas em estufa com ventilação forçada $\left(55^{\circ} \mathrm{C}\right)$ por 72 horas e processadas em moinhos do

Tabela 1 - Composição em ingredientes e composição química das dietas (\% da MS)

Table 1 - Proportion of the ingredient and the composition of diets (\% in dry matter)

\begin{tabular}{|c|c|c|c|}
\hline \multirow{2}{*}{$\begin{array}{l}\text { Ingredientes } \\
\text { Ingredient }\end{array}$} & \multicolumn{3}{|c|}{$\begin{array}{c}\text { Tratamentos } \\
\text { Treatments }\end{array}$} \\
\hline & $\begin{array}{c}\text { FS } \\
S B M\end{array}$ & $\begin{array}{l}\text { Uréia } \\
\text { Urea }\end{array}$ & $\begin{array}{c}\text { A-150S } \\
\text { Starea }\end{array}$ \\
\hline $\begin{array}{l}\text { Bagaço de cana in natura (BIN) } \\
\text { In natura sugarcane bagasse }\end{array}$ & 20,5 & 20,5 & 20,5 \\
\hline $\begin{array}{l}\text { Milho moído } \\
\text { Ground corn }\end{array}$ & 27,5 & 33,2 & 30,9 \\
\hline $\begin{array}{l}\text { Polpa cítrica } \\
\text { Citrus pulp }\end{array}$ & 33,1 & 41,0 & 41,0 \\
\hline $\begin{array}{l}\text { Farelo de soja (FS) } \\
\text { Soybean meal (SBM) }\end{array}$ & 16,5 & - & - \\
\hline $\begin{array}{l}\text { Uréia } \\
\text { Urea }\end{array}$ & - & 2,46 & - \\
\hline $\begin{array}{l}\text { Amiréia(A-150S) } \\
\text { Starea }\end{array}$ & - & - & 4,78 \\
\hline $\begin{array}{l}\text { Mistura mineral }^{1} \\
\text { Mineral mix }\end{array}$ & 1,37 & 1,37 & 1,37 \\
\hline $\begin{array}{l}\text { Cloreto de potássio } \\
\text { Potass chloride }\end{array}$ & - & 0,41 & 0,41 \\
\hline $\begin{array}{l}\text { Bicarbonato de sódio } \\
\text { Sodium bicarbonate }\end{array}$ & 1,09 & 1,09 & 1,09 \\
\hline
\end{tabular}

\begin{tabular}{|c|c|c|c|}
\hline \multicolumn{4}{|l|}{$\begin{array}{l}\text { Composição química } \\
\text { Chemical composition }\end{array}$} \\
\hline MS (\% da matéria natural) & 73,4 & 74,3 & 71,4 \\
\hline \multicolumn{4}{|l|}{$D M(\%$ original matter $)$} \\
\hline $\begin{array}{l}\text { Proteína bruta } \\
\text { Crude protein }\end{array}$ & 13,4 & 13,2 & 13,2 \\
\hline \multicolumn{4}{|l|}{ Neutral detergent fiber } \\
\hline $\begin{array}{l}\text { Fibra em detergente ácido } \\
\text { Acid detergente fiber }\end{array}$ & Acid detergente fiber & 24,2 & 24,1 \\
\hline $\begin{array}{l}\text { Carboidratos não fibrosos }{ }^{2} \\
\text { Non fiber carbohydrates }\end{array}$ & 50,1 & 50,4 & 51,0 \\
\hline $\begin{array}{l}\text { Matéria mineral } \\
\text { Ash }\end{array}$ & 4,3 & 3,8 & 3,8 \\
\hline \multicolumn{3}{|l|}{ Ether extract } & 3,7 \\
\hline $\begin{array}{l}\text { Lignina } \\
\text { Lignin }\end{array}$ & 4,3 & 4,6 & 4,5 \\
\hline \multicolumn{4}{|c|}{ 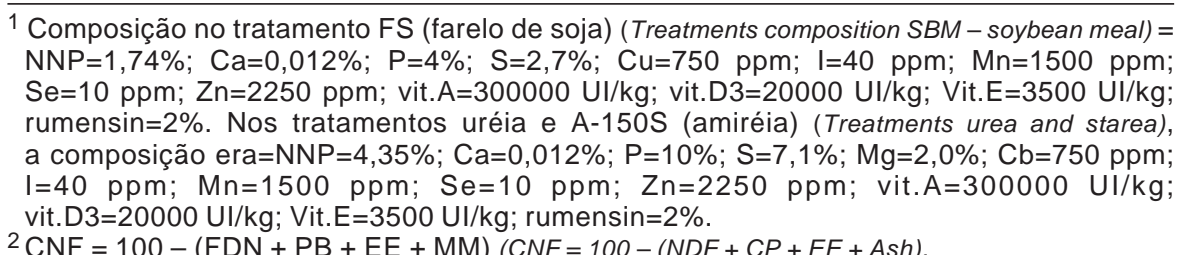 } \\
\hline
\end{tabular}


tipo Wiley (Marconi, Piracicaba, SP); primeiramente em peneira de $2 \mathrm{~mm}$ e após em peneira de $1 \mathrm{~mm}$. Posteriormente, todas estas amostras voltaram a estufa, por 12 horas a $105^{\circ} \mathrm{C}$ para determinação de matéria seca de acordo com a metodologia descrita por Silva (1990).

A determinação de matéria mineral (MM), extrato etéreo (EE) e nitrogênio foi realizada de acordo com AOAC (1990); fibra em detergente neutro (FDN) e fibra em detergente ácido (FDA), de acordo com o métodos descritos por Van Soest et al. (1991), não seqüencial, utilizando amilase e sulfito de sódio nas determinações de FDN e lignina de acordo com a metodologia descrita por Goering \& Van Soest, (1970). Os carboidratos não fibrosos (CNF) pela fórmula: $100-($ FDN + PB + EE + MM) descrita por Sniffen et al. (1992). O nitrogênio das fezes foi analisado no macro Kjeldahl segundo a AOAC (1990).

A colheita total de urina foi realizada durante 48 horas (15ํㅜ $16^{\circ}$ dias), em todos os subperíodos, sendo colhida a cada 24 horas (Valadares et al., 1997a). Foram utilizados funis (napa) fixados por alças elásticas no dorso dos animais (Valadares et al., 1997b). A urina foi conduzida por intermédio de mangueira de borracha até um saco plástico contendo 200 mL de solução de ácido sulfúrico a 30\%, mantendo o pH final da urina sempre menor que 3,0. Após a pesagem e homogeneização da urina, esta foi filtrada em gaze cirúrgica, colhendo-se aproximadamente $30 \mathrm{~mL}$, sendo colocada em frascos de vidro com tampa e armazenada a $-10^{\circ} \mathrm{C}$ para posterior análise (Chen \& Gomes, 1992). O nitrogênio da urina foi analisado no macro Kjeldahl segundo a AOAC (1990).

As amostras de conteúdo ruminal foram colhidas no penúltimo dia de colheita de cada subperíodo (17ํㅜำ dia), com intervalos de duas horas entre cada colheita. Os horários de colheita foram determinados obedecendo aos horários da alimentação, sendo que a hora zero foi antes do fornecimento da dieta pela manhã e 2, 4, 6, 8 e 10 horas após o fornecimento da dieta.

As amostras de conteúdo ruminal foram colhidas de quatro pontos diferentes da cavidade e depois filtrada em duas camadas de tecido de algodão (fraldas), obtendo-se, desta forma, aproximadamente $200 \mathrm{~mL}$ de fluido ruminal filtrado, retirando-se uma alíquota de $25 \mathrm{~mL}$, acrescentando 1,25 mL de solução $6 \mathrm{~N}$ de ácido clorídrico e conservando-a congelada a $-10^{\circ} \mathrm{C}$

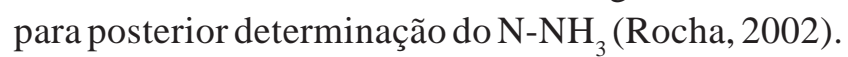

Após o descongelamento, as amostras de fluido ruminal foram centrifugadas a $11.000 \mathrm{~g} \mathrm{a} 4^{\circ} \mathrm{C}$, durante 20 minutos, sendo que uma fração do sobrenadante foi utilizada para análise de $\mathrm{N}-\mathrm{NH}_{3}$, segundo o método calorimétrico descrito por Chaney \& Marbach (1962) e adaptado para ser usado em placas de microtítulo e posterior leitura em aparelho do tipo "ELISA READER” (absorvância de 550 nanômetros), o qual apresenta os resultados em $\mathrm{mg} / \mathrm{dL}$.

As amostras de sangue foram colhidas no último dia de colheita de cada subperíodo (18o dia). As amostras de sangue foram colhidas na veia coccigena, em tubos "vacuntainer" contendo oxalato de potássio (anticoagulante) e fluoreto de sódio (anti-glicolítico). Os horários de colheita de sangue para determinação de nitrogênio uréico plasmático foram determinados obedecendo o horário da alimentação, sendo que a hora zero foi antes do fornecimento da dieta pela manhã e 2, 4, 6, 8 e 10 horas após o fornecimento da dieta.

Foi utilizado apenas o horário das 4 horas após a alimentação para determinação de glicose no plasma. As amostras foram centrifugadas a $4.000 \mathrm{~g}$ por 20 minutos à temperatura de $4^{\circ} \mathrm{C}$ para separação do plasma sangüíneo, o qual foi acondicionado em tubos do tipo "ependorf” e armazenado a $-10^{\circ} \mathrm{C}$ para posteriores análises.

O nitrogênio uréico plasmático foi determinado por intermédio do método enzimático colorimétrico (“Kit” Labtest Diagnóstico SA, Lagoa Santa, MG), multiplicando-se o valor obtido por 0,45 (uréia contém $45 \%$ de N) para obter o nitrogênio uréico. A concentração plasmática de glicose foi determinada utilizando um método enzimático colorimétrico (“Kit” Laborlab Produtos para Laboratórios LTDA, Guarulhos, SP).

O experimento foi conduzido em um delineamento experimental quadrado latino $3 \times 3$ duplicado (seis animais e três tratamentos), adotando-se para análise estatística o procedimento GLM do programa estatístico SAS (1988). As variáveis $\mathrm{N}^{-\mathrm{NH}_{3}}$ e N-uréico foram analisadas estatisticamente como parcelas subdivididas no tempo utilizando o procedimento MIXED, que define as variáveis fixas e aleatórias para execução da análise. Os efeitos de tratamento, animal e período foram testados com relação às parcelas. A interação horário de colheita $\mathrm{x}$ tratamentos foi testada com relação às subparcelas. Para as variáveis que obtiveram respostas significativas no teste $F$, utilizou-se o teste Tukey e o comando LSMEANS/PDIFF para verificar as diferenças entre os tratamentos, em nível de significância de 5\%. 


\section{Resultado e Discussão}

Nitrogênio amoniacal: Os valores de nitrogênio amoniacal no fluido ruminal para os tratamentos nos vários horários de colheita estão apresentados na Tabela 2. Houve diferença $(\mathrm{P}<0,05)$ nos valores médios de nitrogênio amoniacal entre tratamentos (parcelas) e na variação média durante o dia (subparcelas) e nos tratamentos uréia e amiréia. A interação tratamento $\mathrm{x}$ horários apresentou tendência $(\mathrm{P}<0,10)$.

Os tratamentos apresentaram picos de nitrogênio amoniacal por volta de duas horas após a alimentação (Tabela 2), estando o pico dos tratamentos com fonte de nitrogênio não protéico (uréia e amiréia) de acordo com Owens \& Zinn (1988); porém, o tratamento com farelo de soja deveria ter tido seu pico entre três a quatro horas, segundo os mesmos autores.

No tratamento com farelo de soja, os valores nos horários (subparcelas) são muito próximos, praticamente sem um pico ( $\mathrm{P}>0,05$; Tabela 2 ), o que pode acontecer em dietas com baixa porcentagem de proteína (Owens \& Zinn, 1988). No entanto, as dietas do atual experimento não são baixas em proteína total (Tabela 1), mas o tratamento com farelo de soja deficiente em PDR (NRC, 1996 e Fox et al., 2000) pode ter promovido redução na taxa de digestão e no consumo de matéria seca, por falta de amônia para as bactérias ruminais (Tedeschi etal., 2000).

As bactérias fermentadoras de carboidratos fibrosos utilizam amônia como única fonte de nitrogênio, sendo estas altamente prejudicadas quando ocorre deficiência de nitrogênio degradável no rúmen (PDR), levando a menor desaparecimento dos carboidratos fibrosos, diminuindo a taxa de passagem e, conseqüentemente, o consumo de MS (Tedeschi et al., 2000).

O menor $(\mathrm{P}<0,05)$ valor da concentração do nitrogênio amoniacal no fluido ruminal do tratamento com deficiência em PDR (farelo de soja) comparado ao de uréia provavelmente ocorreu em razão da menor degradabilidade da proteína (balanço de nitrogênio ruminal negativo - NRC, 1996 e Fox et al., 2000) neste tratamento. Segundo Devant et al. (2001), em dietas com alto teor de concentrado, a degradabilidade da PB do farelo de soja diminui, limitando a disponibilidade de amônia e ácidos graxos voláteis de cadeias ramificadas. No mesmo sentido, a taxa de produção de peptídeos é reduzida em 50\% com adição de ionóforo (Russel, 1994). Com o aumento no consumo de proteína degradável, Milton et al. (1997), Shain et al. (1998) e Fu et al. (2001) observaram aumento linear na concentração de nitrogênio amoniacal em novilhos

Tabela 2 - Concentração de nitrogênio amoniacal no fluido ruminal (mg/dL) em bovinos de corte alimentados com dietas contendo diferentes fontes nitrogenadas

Table 2 - Ruminal ammonia- $N$ concentration $(\mathrm{mg} / \mathrm{dL}$ ) in beef cattle supplemented with nitrogenous sources

\begin{tabular}{ccccc}
\hline $\begin{array}{c}\text { Horas }^{2} \\
\text { Hours }\end{array}$ & \multicolumn{3}{c}{$\begin{array}{c}\text { Tratamentos }^{1} \\
\text { Treatments }\end{array}$} & $\begin{array}{c}\text { Subparcelas } \\
\text { Subplots }\end{array}$ \\
\cline { 2 - 3 } & FS & Uréia & A-150S & \\
Urea & Starea & \\
\hline 0 & $15,0^{\mathrm{a}}$ & $15,8^{\mathrm{b}}$ & $11,3^{\mathrm{b}}$ & $17,3^{\mathrm{b}}$ \\
2 & $17,9^{\mathrm{Ba}}$ & $28,6^{\mathrm{Aa}}$ & $23,4^{\mathrm{ABa}}$ & $23,3^{\mathrm{a}}$ \\
4 & $12,9^{\mathrm{Ba}}$ & $22,6^{\mathrm{Aab}}$ & $20,1^{\mathrm{ABab}}$ & $18,5^{\mathrm{ab}}$ \\
6 & $11,8^{\mathrm{Ba}}$ & $22,1^{\mathrm{Aab}}$ & $17,3^{\mathrm{ABab}}$ & $17,1^{\mathrm{b}}$ \\
8 & $13,9^{\mathrm{ABa}}$ & $21,0^{\mathrm{Aab}}$ & $12,3^{\mathrm{Bb}}$ & $15,7^{\mathrm{b}}$ \\
10 & $16,6^{\mathrm{a}}$ & $16,8^{\mathrm{b}}$ & $18,7^{\mathrm{ab}}$ & $17,4^{\mathrm{b}}$ \\
Parcelas $^{4}$ & $14,7^{\mathrm{A}}$ & $21,1^{\mathrm{B}}$ & $17,2^{\mathrm{AB}}$ & \\
Plots & & & & \\
\hline
\end{tabular}

$\mathrm{a}, \mathrm{b}=$ Letras diferentes nas colunas referem-se às médias que diferem entre si pelo teste Tukey $(P<0,05)$ e letras maiúsculas diferentes nas linhas referem-se às médias que diferem entre si pelo teste Tukey $(P<0,10)$; as médias foram ajustadas pelos quadrados mínimos (LSMEANS) (Means, within a column, followed by different small letters, or within a row, followed by different capital letters, are different $[P<.05]$ by Tukey test; the means was adjusted for the least square means [LSMEANS]).

${ }^{1} \mathrm{FS}=$ farelo de soja; $\mathrm{A}-150 \mathrm{~S}=$ amiréia (SBM=soybean meal; starea).

2 Horas após a alimentação (Hours after feeding).

3 Média das subparcelas (horas) (mean of subplots [hours]).

4 Média das parcelas (tratamentos) (mean of plots [treatments]). 
alimentados com dietas com altos teores de grãos.

O tratamento com amiréia não apresentou diferença $(P>0,05)$ na concentração de nitrogênio amoniacal, quando comparado ao tratamento com uréia. Resultado similar foi observado por Shiehzadeh \& Harbers (1975) em ovinos. Em alguns estudos da década de 70 (Hermer et al., 1970; Stiles et al., 1975), a amiréia proporcionou menor concentração de nitrogênio amoniacal quando comparada à uréia mais milho moído, mas, quando se substituiu o milho moído por extrusado, geralmente não houve diferenças, indicando que a menor concentração de amônia ruminal foi devido ao processamento do grão, e não à liberação gradativa de $\mathrm{N}$.

A concentração de nitrogênio amoniacal no fluido ruminal parece ser resultado de um balanço entre sua utilização pelos microrganismos ruminais e a saída do rúmen através da absorção pela parede do rúmen, efeito que é dependente do $\mathrm{pH}$, ou pelo fluxo para o duodeno junto com a digesta e sua taxa de liberação (Chalupa, 1968). Hoover (1986) debateu extensivamente o intervalo ótimo da concentração de nitrogênio amoniacal (3,3 a 21,5 mg/dL) para síntese de proteína microbiana, demonstrando que é muito variável a concentração de nitrogênio amoniacal para maximizar a síntese de proteína microbiana.

Os valores da concentração de nitrogênio amoniacal apresentados na Tabela 2 estão dentro da faixa proposta por Hoover (1986). No entanto, no tratamento com farelo de soja, a concentração de amônia ruminal (14,7 mg/dL) parece que não foi suficiente para maximizar a síntese de proteína microbiana, uma vez que, neste tratamento, o consumo de MS (Tabela 3) foi inferior, indicando menor síntese de proteína microbiana. Entretanto, estes resultados estão de acordo com Mehrez et al. (1977), que observaram taxa de 95, 85 e $75 \%$ de desaparecimento máximo do substrato com as concentrações de amônia ruminal de 24, 19 e $15 \mathrm{mg} / \mathrm{dL}$, respectivamente.

No presente experimento, não ocorreu menor concentração de nitrogênio amoniacal no tratamento com amiréia quando comparado ao de uréia; talvez, devido à alta concentração de equivalente protéico (150\%) da amiréia utilizada, disponibilizando pouco

\begin{tabular}{|c|c|c|c|c|c|}
\hline \multicolumn{6}{|l|}{$\begin{array}{l}\text { Tratamentos }^{1} \\
\text { Treatments }\end{array}$} \\
\hline Variáveis & FS & Uréia & A-150S & $\mathrm{EPM}^{2}$ & $\mathrm{P}^{3}$ \\
\hline Variables & $S B M$ & Urea & Starea & SEM & $P$ \\
\hline $\begin{array}{l}\text { Consumo de MS, kg/d } \\
\text { DM intake, } \mathrm{kg} / \mathrm{d}\end{array}$ & $5,8^{b}$ & $7,5^{\mathrm{a}}$ & $7,5^{\mathrm{a}}$ & 0,4 & 0,047 \\
\hline $\begin{array}{l}\text { Consumo de N, g/d } \\
N \text { intake, g/d }\end{array}$ & $131,6^{\mathrm{b}}$ & $166,7^{\mathrm{a}}$ & $157,4^{\mathrm{a}}$ & 5,7 & 0,006 \\
\hline $\begin{array}{l}\mathrm{N} \text { nas fezes, } \mathrm{g} / \mathrm{d} \\
\text { Feces } N, \mathrm{~g} / \mathrm{d}\end{array}$ & $24,1^{\mathrm{a}}$ & $28,9^{a}$ & $31,0^{\mathrm{a}}$ & 2,1 & 0,114 \\
\hline $\begin{array}{l}\mathrm{N} \text { na urina, g/d } \\
\text { urinary } N, g / d\end{array}$ & $53,8^{b}$ & $51,2^{\mathrm{b}}$ & $73,1^{\mathrm{a}}$ & 5,5 & 0,044 \\
\hline $\mathrm{N}$ retido, $\mathrm{g} / \mathrm{d}$ & $53,7^{b}$ & $86,6^{\mathrm{a}}$ & $53,2^{\mathrm{b}}$ & 6,7 & 0,011 \\
\hline $\begin{array}{l}N \text { retention, } g / d \\
N \text { retido, } \% \mathrm{~N} \text { consumido }\end{array}$ & $40,8^{\mathrm{b}}$ & $52,0^{\mathrm{a}}$ & $33,7^{\mathrm{b}}$ & 4,1 & 0,022 \\
\hline $\begin{array}{l}N \text { retention, \% of consumed } \\
\text { Valor biológico } \\
\text { ( } \mathrm{N} \text { retido, \% do } \mathrm{N} \text { digerido) } \\
\text { Biological value } \\
(\mathrm{N} \text { retention, \% of digestible } N \text { ) }\end{array}$ & $49,8^{\mathrm{b}}$ & $62,8^{\mathrm{a}}$ & $42,1^{\mathrm{b}}$ & 4,4 & 0,015 \\
\hline
\end{tabular}

\footnotetext{
$a, b=$ Letras diferentes nas linhas referem-se as médias que diferem entre si pelo teste Tukey $(\mathrm{P}<0,05)$; as médias foram ajustadas pelos quadrados mínimos (LSMEANS) (means, in row, with the same letters, did not differ [P>.05] by Tukey test; the means were adjusted for the least square means (LSMEANS).

${ }^{1} \mathrm{FS}=$ farelo de soja (SBM=soybean meal); A-150S=amiréia (starea).

2 EPM=erro-padrão da média (standard error of mean).

${ }^{3} \mathrm{P}=$ probabilidade de haver efeito significativo entre tratamentos.

${ }^{3} P=$ probability of significant effect among treatments.
} 
amido gelatinizado para o animal, o qual não foi suficiente para diminuir a concentração de nitrogênio amoniacal (Wilson \& Woods, 1966; Helmer et al., 1970; Stiles et al., 1975; Simas, 1995; Mendes Jr., 1999).

Os dados de consumo de nitrogênio $(\mathrm{N}), \mathrm{N}$ nas fezes, $\mathrm{N}$ na urina, $\mathrm{N}$ retido e valor biológico da proteína das rações com diferentes fontes de nitrogênio estão apresentados na Tabela 3.

O menor consumo de $\mathrm{N}(\mathrm{P}<0,05)$ no tratamento com farelo de soja foi decorrente, provavelmente, do menor consumo de MS (Tabela 3), já que as dietas eram isoprotéicas (Tabela 1 ).

$\mathrm{O}$ tratamento com uréia proporcionou maior $(\mathrm{P}<0,05)$ retenção de $\mathrm{N}$ ( $\mathrm{g} / \mathrm{d}$ ou \% do $\mathrm{N}$ consumido), que ocorreu principalmente, devido à menor excreção de N proporcional na urina. Calculando-se as proporções de N urinário em relação ao consumo total de N, obtém-se os resultados de 40,9; 30,7 e 46,4\% para farelo de soja, uréia e amiréia, respectivamente. Ou seja, os tratamentos com farelo de soja e amiréia excretaram 10,2 e 15,7 unidades percentuais, respectivamente, mais $\mathrm{N}$ na urina proporcionalmente ao $\mathrm{N}$ consumido, comparado ao tratamento com uréia, o que levou a maior $(\mathrm{P}<0,05)$ valor biológico da proteína no tratamento com uréia, pois aumentou a retenção de $\mathrm{N}$ neste tratamento, uma vez que o $\mathrm{N}$ nas fezes não diferiu $(\mathrm{P}>0,05)$ entre os tratamentos.

Resultado similar da retenção de $\mathrm{N}$ em porcentagem do N consumido foi observado por Silva et al. (1994), em ovinos alimentados com farelo de soja, uréia e amiréia. No entanto, Knaus et al. (2001) não observaram diferenças entre farelo de soja e uréia no $\mathrm{N}$ urinário (57,5 e 54,1 g/d, respectivamente) e no valor biológico da proteína (45,5 e 46,3\%, respectivamente), em novilhos alimentados com ração de alta proporção de concentrado. Os dados de Knaus et al. (2001), referentes ao $\mathrm{N}$ urinário e valor biológico do tratamento com farelo de soja, são similares aos resultados obtidos com farelo de soja, apresentados na Tabela 3.

O maior $(\mathrm{P}<0,05)$ valor biológico da proteína do tratamento com uréia quando comparado ao farelo de soja e amiréia, pode ter sido em razão de maior síntese de proteína microbiana (maior PDR), a qual apresenta melhor perfil de aminoácidos (Santos et al., 1998) e, portanto, maior retenção de N. Estes resultados estão de acordo com a afirmação de Owens \& Zinn (1988), que citaram que o sistema de reciclagem de nitrogênio no rúmen se adapta facilmente à rapidez da liberação de amônia pelas fontes de nitrogênio não protéico, desde que as concentra- ções não atinjam níveis tóxicos. No mesmo sentido, o balanço de nitrogênio ruminal positivo (NRC, 1996; Fox et al., 2000) no tratamento com uréia demonstra indicativo de maior síntese de proteína microbiana em relação ao tratamento com farelo de soja.

Dietas com alto teor de concentrado (milho) têm demonstrado que os peptídeos e/ou aminoácidos do milho devem proporcionar máxima síntese e eficiência de proteína microbiana (Fu et al., 2001; Knaus et al., 2001). Segundo Knaus et al., (2001) o uso de uréia como a única fonte suplementar de $\mathrm{N}$ pode ser utilizada eficientemente para suprir a exigência de proteína metabolizável e aminoácidos, em dietas com alto teor de concentrado, estas afirmações estão de acordo com os resultados apresentados na Tabela 3 , na qual se verificou maior retenção de $\mathrm{N}$ e valor biológico na dieta com uréia.

$\mathrm{O}$ menor $(\mathrm{P}<0,05)$ valor da retenção de $\mathrm{N}$ no tratamento com amiréia quando comparado ao de uréia, não apresenta uma explicação lógica, sendo a principal causa, a maior excreção de $\mathrm{N}$ na urina (21,9 unidades percentuais a mais; Tabela 3). Um fator que deve ser considerado, segundo Van Soest (1994), é que produtos da reação de Millard podem aparecer na fração solúvel da proteína e serem absorvidos, mas não são metabolizados e são excretados na urina, sendo que a maioria destes compostos passam direto pelos intestinos, saindo nas fezes. Isso pode ter acontecido devido à possibilidade de ocorrer reações de Millard no procedimento de fabricação da amiréia e na tostagem da soja para confecção do farelo.

Salman et al. (1997) observaram maior excreção de $\mathrm{N}$ na urina no tratamento com amiréia $(7,7 \mathrm{~g} / \mathrm{d})$, em relação ao farelo de algodão (4,8 g/d), semelhantes aos do tratamento com uréia (6,5 g/d), em ovinos. Os mesmos autores não observaram alterações no valor biológico da proteína $(73,1 ; 58,1$ e 57,6\%, para farelo de algodão, uréia e amiréia, respectivamente).

Contrariando os resultados apresentados na Tabela 3, Shiehzadeh \& Harbers (1974) observaram maior retenção de $\mathrm{N}$ no tratamento com amiréia comparado à uréia, em ovinos. Teller \& Godeau (1986) também não observaram alterações na retenção de $\mathrm{N}$ entre rações com farelo de soja, uréia e amiréia em vacas lactantes.

São necessários mais trabalhos que avaliem o balanço de nitrogênio em bovinos de corte, além da necessidade de determinações da síntese de proteína microbiana, pois a amiréia apresenta uma fonte de 
amido com alta taxa de degradação e uma suposta liberação mais lenta de amônia. Assim, é de se esperar maior síntese de proteína microbiana, a qual apresenta alto valor biológico, portanto, maior retenção de nitrogênio. Isso não foi observado neste experimento, indicando que os efeitos da amiréia não estão sendo suficientes para aumentar a retenção de nitrogênio.

Parâmetros sangüíneos: Os valores de nitrogênio uréico e glicose no plasma sangüíneo para os tratamentos, estão apresentados na Tabela 4. Não houve diferença $(\mathrm{P}>0,05)$ nos valores médios de nitrogênio uréico dos tratamentos (parcelas). A variação durante o dia (subparcelas) e a interação tratamento x horários não apresentaram alterações ( $\mathrm{P}>0,05)$.

Resultados similares foram observados por Jones et al. (1975) e Carmo (2001) na primeira fase do experimento, em vacas, e Fernandes (2002) na oitava semana, em cabras, quando utilizaram as mesmas fontes nitrogenadas do atual experimento. O mesmo foi observado em cordeiros por Shiehzadeh \& Harbers (1974) entre amiréia e uréia, e por Knaus et al. (2001) em novilhos em crescimento alimentados com uréia e farelo de soja, sendo os teores de PB próximos aos do atual experimento (13,7\%). Entretanto, Schmidt et al. (1973), utilizando novilhos, observaram menor concentração de nitrogênio uréico no tratamento de farelo de soja, quando comparado aos de uréia e amiréia.

A uréia é sintetizada pelo fígado a partir do $\mathrm{N}-\mathrm{NH}_{3}$, a qual é produzida durante o catabolismo das proteínas. O organismo gasta energia considerável para produzir a uréia, a fim de evitar a toxicidade por $\mathrm{N}-\mathrm{NH}_{3}$ (Swenson \& Reece, 1996). Com base nessa afirmação, pode-se inferir que os teores de proteína bruta das dietas estavam em excesso, já que apresentaram altas concentrações de nitrogênio uréico no plasma, tanto para o tratamento com deficiência em PDR quanto para os ajustados em PDR (uréia e amiréia). As concentrações de uréia sangüínea têm sido utilizadas para monitorar o consumo de proteína dietética próximo as exigências do animal, já que o consumo excessivo de proteína pode afetar o desempenho reprodutivo do animal, elevando sua exigência em energia, ou ainda aumentar o custo da ração (Broderick \& Clayton, 1997).

O nitrogênio uréico plasmático (NUP) não é bom indicador de consumo de proteína, mas pode ser bom indicador da proteína não utilizada (Staples et al., 1993). Isso reforça a hipótese de que os animais do atual experimento não estavam sendo capazes de utilizar boa parte da proteína consumida, uma vez que os valores de NUP foram altos (maiores que $16 \mathrm{mg} / \mathrm{dL}$; Tabela 4).

Staples et al. (1993) sugeriram que valores de NUP acima de $16 \mathrm{mg} / \mathrm{dL}$ podem incidir problemas reprodutivos em vacas lactantes. Os valores do atual experimento ficaram sempre acima deste ( $\mathrm{Ta}$ bela 4), merecendo mais estudos sobre o assunto em bovinos de corte. Embora a maioria dos animais confinados seja destinada ao abate, este assunto torna-se menos relevante.

Staples et al. (1993) concluíram que um horário

Tabela 4 - Concentração de N-uréico e de glicose no plasma sangüíneo em bovinos de corte suplementados com fontes nitrogenadas

Table 4 - Plasma urea- $N$ and glucose concentration in beef cattle supplemented with nitrogenous sources

\begin{tabular}{|c|c|c|c|c|}
\hline \multirow{2}{*}{$\begin{array}{l}\text { Variáveis } \\
\text { Variable }\end{array}$} & \multicolumn{3}{|c|}{$\begin{array}{c}\text { Tratamentos }^{1} \\
\text { Treatments }\end{array}$} & \multirow{2}{*}{$\begin{array}{r}\mathrm{EPM}^{2} \\
S B M\end{array}$} \\
\hline & $\begin{array}{c}\text { FS } \\
\text { SEM }\end{array}$ & $\begin{array}{l}\text { Uréia } \\
\text { Urea }\end{array}$ & $\begin{array}{c}\text { A-150S } \\
\text { Starea }\end{array}$ & \\
\hline $\begin{array}{c}\text { N-uréico, mg/dL } \\
\text { Urea- } N, m g / d L \\
\text { Glicose, } \mathrm{mg} / \mathrm{dL}\end{array}$ & $20,9^{a}$ & $17,8^{\mathrm{a}}$ & $18,5^{\mathrm{a}}$ & 1,93 \\
\hline Glucose, $\mathrm{mg} / \mathrm{dL}$ & $62,2^{\mathrm{a}}$ & $65,2^{\mathrm{a}}$ & $69,8^{\mathrm{a}}$ & 7,85 \\
\hline
\end{tabular}

$\mathrm{a}, \mathrm{b}=$ Letras diferentes nas linhas referem-se às médias que diferem entre si pelo teste

Tukey $(\mathrm{P}<0,05)$; as médias foram ajustadas pelos quadrados mínimos (LSMEANS) (means,

in row, with the same letters, did not differ [P>.05] by Tukey test; the means were adjusted for the least square means (LSMEANS) (FS=farelo de soja).

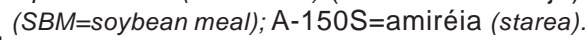

$1 \mathrm{FS}=$ farelo de soja (SBM=soybean meal); A-150S=amiréia (starea).

2 EPM=erro-padrão da média (standard error of mean). 
para se obter valor representativo de NUP, em vacas leiteiras, está entre 6 e 7 horas após a alimentação. Neste experimento, o melhor horário (8 horas após a alimentação) foi muito próximo à do intervalo proposto por aqueles autores, embora não tenha sido avaliado na hora 7.

Não houve diferença $(P>0,05)$ nos valores médios de glicose plasmática entre os tratamentos. Resultados similares foram observados por Carmo (2001) em vacas leiteiras e Fernandes (2002) em cabras leiteiras, quando utilizaram as mesmas fontes nitrogenadas do presente experimento. O mesmo foi observado por Knaus et al. (2001) em novilhos em crescimento alimentados com uréia e farelo de soja, sendo os teores de PB próximos aos do presente estudo (13,7\%).

Visek (1984), em uma revisão, citou que a arginina aumenta a insulina no plasma, nos testes de tolerância à glicose em ratos, e, conseqüentemente, a taxa de renovação de glicose do sangue. O autor sugeriu também que a deficiência de arginina pode levar a insulina presente na circulação a não ter efeito na circulação da glicose. Nos períodos de alta absorção de amônia, a arginina é usada no processo de desintoxicação pela síntese de uréia, podendo, portanto, não estar disponível em quantidade suficiente para potencializar a liberação e o efeito da insulina. Com base neste conhecimento, pode-se inferir que as quantidades de NNP (uréia ou amiréia) utilizadas (Tabela 1) não foram metabolicamente prejudiciais para os animais, já que não diferiu a concentração de glicose entre os tratamentos (Tabela 4).

\section{Conclusões}

A suplementação com dieta adequada em PDR contendo uréia promoveu maior retenção de nitrogênio e melhor valor biológico da proteína em bovinos de corte, quando comparado ao uso de uma fonte de proteína verdadeira (farelo de soja) sem atender às exigências em PDR ou atendê-las com amiréia.

A uréia promove maior concentração de amônia ruminal quando comparada com o farelo de soja, ambos similares à amiréia.

As fontes nitrogenadas não alteraram a concentração de nitrogênio uréico e de glicose no plasma.

\section{Literatura Citada}

ASSOCIATION OF OFFICIAL ANALYTICAL CHEMISTS AOAC. Official methods of analysis. 15.ed. Arlington, D.C.: 1990. 1117p.

BARTLEY, E.E.; DEYOE, C.W. Starea as a protein replacer for ruminants - review of 10 years of research. Feedstuffs, v.47, n.30, p.42-44, 1975.

BRODERICK, G.A.; CLAYTON, M.K. A statistical of animal and nutrition factors influencing concentrations of milk urea nitrogen. Journal of Dairy Science, v.80, p.2964-2971, 1997.

BULLE, M.L.M.; RIBEIRO, F.G.; LEME, P.R. et al. Desempenho de tourinhos cruzados em dietas de alto teor de concentrado em bagaço de cana-de-açúcar como único volumoso. Revista Brasileira de Zootecnia, v.31, n.1, p.444-450, 2002.

CARMO, C.A. Substituição do farelo de soja por uréia ou amiréia em dietas para vacas leiteiras. Piracicaba: Escola Superior de Agricultura "Luiz de Queiroz", 2001. 74p. Dissertação (Mestrado) - Escola Superior de Agricultura "Luiz de Queiroz", 2001.

CHALUPA, W. Problems in feed urea to ruminants. Journal of Animal Science, v.27, p.207-219, 1968.

CHANEY, A.L.; MARBACH, E.P. Modified reagents for determination of urea and ammonia. Clinical Chemistry, v.8, p.130-146, 1962.

CHEN, X.B.; GOMES, M.J. Estimation of microbial protein supply to sheep and cattle based on urinary excretion of purine derivatives. An overview of technical details. International Feed Resources Unit, Occasional Publication. Aberdeen, United Kingdom: Rowett Researsh Institute, 1992. 21p.

DEVANT, M.; FERRET, A.; CALSAMIGLIA, S. et al. Effect of nitrogen source in high-concentrate, low, protein beef cattle diets on microbial fermentation studied in vivo and in vitro. Journal of Animal Science, v.79, p.1944-1953, 2001.

FERNANDES, R.H.R. Substituição parcial do farelo de soja por uréia ou amiréia em dietas para cabras em lactação. Piracicaba: Escola Superior de Agricultura “Luiz de Queiroz”, 2001. 72p. Dissertação (Mestrado) - Escola Superior de Agricultura "Luiz de Queiroz”, 2002.

FOX, D.G.; TYLUTKI, T.P.; Van AMBURGH, M.E. et al. The net carbohydrate and protein system for evaluating herd nutrition and nutrient excretion. Model Documentation. Ithaca: Cornell University, 2000. 235p.

FU, C.J.; FELTON, E.E.D.; LEHMKUHLER, J.W. et al. Ruminal peptide concentration required to optimize microbial growth and efficiency. Journal of Animal Science, v.79, p.1305-1312, 2001.

GOERING, H.K.; Van SOEST, P.J. Forage fiber analysis (Apparatus, reagents, procedures and some applications). Agricultural Handbook. Washington D.C.: Agricultural Research Service, 1970. p.19.

HELMER, L.G.; BARTLEY, E.E.; DEYOE, C.W. et al. Feed 
processing. 5. Effect of an expansion-processed mixture of grain and urea (starea) on nitrogen utilization in-vitro. Journal of Dairy Science, v.53, n.3, p.330-335, 1970.

HENRIQUE, W.; LEME. P.R.; LANNA, D.P.D. et al. Avaliação do milho úmido com bagaço de cana ou silagem de milho na engorda de bovinos. I. Desempenho animal e características de carcaça. In: REUNIÃO ANUAL DA SOCIEDADE BRASILEIRA DE ZOOTECNIA, 36., 1999, Porto Alegre. Anais... Porto Alegre: Sociedade Brasileira de Zootecnia, 1999. p.307.

HOOVER, W.H. Chemical factors involved in ruminal fiber digestion. Journal of Animal Science, v.69, p.2755-2766, 1986.

JONES, G.M.; STEPHENS, C.; KENSETT, B. Utilization of starea, urea, or soybean-meal in complete rations for lactating dairy-cows. Journal of Dairy Science, v.58, n.5, p.689-695, 1975.

KNAUS, W.F.; BEERMANN, D.H.; GUIROY, P.J. et al. Optimization of rate and efficiency of dietary nitrogen utilization through the use of animal by-products and (or) urea and their effects on nutrient digestion in Holstein steers. Journal of Dairy Science, v.78, p.1060-1066, 2001.

MENDES JR., M.P. Efeito do processamento do grão de milho e sua substituição parcial por polpa de citros peletizada sobre o desempenho, digestibilidade de nutrientes e parâmetros sanguíneos de vacas de leite. Piracicaba: Escola Superior de Agricultura “Luiz de Queiroz”, 1999. 97p. Dissertação (Mestrado) - Escola Superior de Agricultura “Luiz de Queiroz”, 1999.

MEHRES, A.Z.; ØRSKOV, E.R.; McDONALD, I. Rates fermentation in relation to ammonia concentration. The British Journal of Nutrition, v.38, n.3, p.437-443, 1977.

MILTON, C.T.; BRANDT JR., R.T.; TITGEMEYER, E.C. Urea in dry-rolled corn diets: finishing steer performance, nutrient digestion, and microbial protein production. Journal of Animal Science, v.75, p.1415-1424, 1997.

NATIONAL RESEARCH COUNCIL - NRC. Nutrient requirements of beef cattle. 6.ed. Washington, D.C.: National Academy Press, 1984. 89p.

NATIONAL RESEARCH COUNCIL - NRC. Nutrient requirements of beef cattle. 7.ed. Washington, D.C.: National Academy Press, 1996. 242p.

OWENS, F.N.; ZINN, R. Protein metabolism of ruminant animal. In: CHURCH, D.C. (Ed.) The ruminant animal: digestive physiology and nutrition. Englewood Cliffs: Simon \& Schuster, 1988. p.227-249.

ROCHA, M.H.M. Teores de proteína bruta em dietas com alta proporção de concentrado para cordeiros confinados. Piracicaba: Escola Superior de Agricultura "Luiz de Queiroz”, 2002.73p. Dissertação (Mestrado) - Escola Superior de Agricultura “Luiz de Queiroz”, 2002.

RUSSEL, J.B. Factors influencing rumen microbial growth and protein yield. In: SOUTHWEST NUTRITION MANAGEMENT CONFERENCE, Arizona, 1994. Proceedings... Arizona: University of Arizona, 1994. p.1-6.

RUSSEL, J.B.; O`CONNOR, J.D.; FOX, D.G. et al. A net carbohydrate and Protein System for evaluating cattle diets: I. Ruminal fermentation. Journal of Animal Science, v.70, p.3551-3561, 1992.

SALMAN, A.K.D.; MATARAZZO, S.V.; EZEQUIEL, J.M.B. et al. Estudo do balanço nitrogenado e da digestibilidade da matéria seca e proteína de rações, para ovinos, suplementadas com amiréia, uréia ou farelo de algodão. Revista Brasileira de Zootecnia, v.26, p.179-185, 1997.

SANTOS, F.A.P. Efeito de fontes protéicas e processamento de grãos no desempenho de vacas leite e digestibilidade dos nutrientes. Piracicaba: Escola Superior de Agricultura “Luiz de Queiroz”, 1998. 105p. Tese (Livre Docência) Escola Superior de Agricultura "Luiz de Queiroz”, 1998.

STATISTICAL ANALYSIS SYSTEM - SAS. SAS/STAT User's guide. Cary: 1988.

SCHMIDT, S.P.; JORGENSE, N.A.; BENEVENG, N.J. et al. Comparison of soybean-meal, formaldehyde treated soybeanmeal, urea and starea for steers. Journal of Animal Science, v.37, p.1233-1237, 1973.

SILVA, D.J. Análise de alimentos: métodos químicos e biológicos. Viçosa, MG: Universidade Federal de Viçosa, 1990, 166p.

SILVA, J.F.C; PEREIRA, J.C.; VALADARES FILHO, S.C. et al. Valor nutritivo da palha de arroz suplementada com amiréia, fubá+uréia e farelo de soja. Pesquisa Agropecuária Brasileira, v.29, p.1475-14881, 1994.

SIMAS, J.M.C. Effect of sorghum grain processing and fat supplementation on performance and nutrient utilization in lactating dairy cows. Tucson, AZ: University of Arizona 1995. 147p. Thesis (PhD) - University of Arizona., 1995.

SHAIN, D.H.; STOCK, R.A.; KLOPFENSTEIN, T.J. et al. Effect of degradable intake protein level on fishing cattle performance and ruminal metabolism. Journal of Animal Science, v.76, p.242-248, 1998.

SHIEHZADEH, S.A.; HARBERS, L.H. Soybean meal, urea and extruded starch-urea products compared as protein supplements in high-roughage lamb rations. Journal of Animal Science, v.38, p.206-212, 1974.

SNIFFEN, C.J.; O’COMMOR, J.D.; Van SOEST, P.J. et al. A net-carbohydrate and protein system for evaluating cattle diets: II. Carbohydrate and protein availability. Journal of Animal Science, v.70, p.3562-3577, 1992.

STAPLES, C.R.; GARCIA-BOJALIL, C.; OLDICK, B.S. et al. Protein intake and reproductive performance of dairy cows: a review, a suggested mechanism, and blood and milk urea measurements. In: ANUNUAL FLORIDA RUMINANT NUTRITION SYMPSIUM, 4., 1993, Gainesville. Proceedings ... Gainesville: University of Florida, 1993. p.37-52.

STILES, D.A.; LEE, D.D.; BARTLEY, E.E. Starea, soybeanmeal, and urea as nitrogen-sources for lactating cows. Journal of Dairy Science, v.58, n.5, p.777-778, 1975.

SWENSON, M.J.; REECE, W.O. Fisiologia dos animais domésticos. 11.ed. Rio de Janeiro: Guanabara Koogan, 1996. 856p.

TEDESCHI, L.O.; FOX, D.G.; RUSSELL, J.B. Accounting for the effects of a ruminal nitrogen deficiency within the structure of the Cornell Net Carbohydrate and Protein System. Journal of Animal Science, v.78, p.1648-1658, 2000.

TELLER, E.; GODEAU, J.M. Some attempts to improve the nutritive value of urea for dairy cows. 3 . Its adjunction to fermentable carbohydrates: starea. Archiv fur Tierernahrung - Archives of Animal Nutrition, v.36, n.6, p.541-550, 1986.

TELLER, E.; GODEAU, J.M.; DEBAERE, B. La substitution du "starea" aux tourteaux dans les rations pour vaches en 
lactation. Revue de l’Agriculture, v.35, p.3171-3179, 1982.

VALADARES, R.F.D; GONÇALVES, L.C.; RODRIGUEZ, N.M. et al. Metodologia de coleta de urina em vacas utilizando sondas de folley. Revista Brasileira de Zootecnia, v.26, n.6, p.1297-1282, 1997a.

VALADARES, R.F.D; GONÇALVES, L.C.; SAMPAIO, I.B. et al. Níveis de proteína em dietas de bovinos. 2. Consumo, digestibilidade e balanço de compostos nitrogenados. Revista Brasileira de Zootecnia, v.26, n.6, p.1259-1263, 1997b.

Van SOEST, P.J. Nutrition ecology of the ruminant. 2.ed. Ithaca: Cornell University Press, 1994. 476p.

Van SOEST, P.J.; ROBERTSON, J.B.; LEWIS, B.A. Methods for dietary fiber, neutral detergent fiber, and nonstarch polysaccharides in relation to animal nutrition. Journal of Dairy Science, v.74, p.3583-3597, 1991.
VISEK, W.J. Ammonia: its effects on biological systems, metabolic hormones, and reproduction. Journal of Dairy Science, v.67, n.3, p.481-498, 1984.

WILSON, B.B.; WOODS, W. Effect of level of gelatinized corn upon animal performance and rumen fermentation. Journal of Animal Science, v.25, p.912-912 (Abstr.), 1966.

Recebido em: 10/12/02

Aceito em: 30/10/03 